\title{
Faculty's Perceptions Of Teaching Ethics And Leadership In Engineering Education
}

Abdullah AlSagheer, Hamdan Bin Mohammad e-University, UAE Areej Al-Sagheer, Kuwait Petroleum International, Kuwait

\begin{abstract}
This paper addressed the faculty's perception of engineering ethics and leadership training. The study looks into the present state of and methodologies for teaching engineering ethics and leadership and aims to determine the faculty's perception of an identified gap in this aspect of engineering education. Engineering education has strong ethics and leadership training requirements; however, universities focused on mastering the education of students in this discipline are still ignoring training in these areas. The authors conducted interviews to determine the perspective on this topic of faculty members teaching at different engineering institutes. Core reasons for underestimating the importance of these disciplines are linked with faculty perceptions. Through these interviews, the authors found that faculties are treating engineering education in two parts. Faculty perceptions are that students can do the technical coursework portion of their education during the academic period, while their ethical and leadership training can be deferred until their professional career attains its peak.
\end{abstract}

Keywords: engineering ethics; leadership; engineering education; professional career; faculty perspective

\section{INTRODUCTION}

The need for ethics education is closely aligned with the importance of the faculty's role in education, in general. Faculties play an important role in the establishment of virtues and vice and in the promotion of virtues and vices in society. A society and its values are formed, to a great extent, by its educational faculties, so it is necessary to know the level of ethical development within those faculties. Professional faculties strive for excellence of environment and they try to foster those factors that can help students to develop and improve their moral character.

Along with ethical guidance, faculty members prepare their students for the challenges of professional life. A major challenge includes the development of students' leadership abilities, which usually need to be "buffed up" by faculties. Faculties' perception of the role of leadership and its requirement in professional life is important. To prepare students for a professional life and to guide their ethical lives, an assessment of faculty members' personal views about the role of ethics education is required (Amjad, 2008). This information, based specifically on engineering faculty members' perception of the role of ethics and leadership in their students' education, subsequently takes the lead in helping to identify the needs that currently exist in this area.

From the initial stages of their career, engineers are the ones who are expected to lead a project; as the backbone of the project, they can make or break it. Therefore, instilling leadership skills in engineers as leaders is particularly imperative (Hinkle, 2007). The engineer also is the one who plays the role of project manager later in his career. Engineers are and need to be influential. They are required to play a primary role in innovation that may benefit organizations and their customers over time. At the same time, engineers always face the issue of trade-offs between costs to the company and benefits to customers. For example, the lowest cost will return the highest profits, and this fact may spur engineers to overlook their professional ethical standard of quality and integrity. So it is critical to ensure that, in spite of the greatest urge for profits, an engineer always works under professional ethical 
standards. Also, during the academic period, it is faculty members who may incorporate both leadership and ethical standards in their students.

Ethics is defined as standards that apply to everyone and that are the standard every rational person wants others to follow (Harris, Davis, Pritchard, and Rabins, 1996). The term ethics has roots in Greek philosophy. Ethics has a principle concern with the nature of human well-being. According to the notion of Aristotle, the virtues are a central part of one's life. He suggests that ethical values, such as justice, courage, and temperance, are complex rational, emotional, and social skills, and that one may learn the skills over time during his interaction with other social beings (Norman, 1984). Professional ethics refer to that special, morally permissible standard of conduct that, ideally, every member of a profession wants every other member to follow. Professional ethical standards apply to every member of the group since they belong to the same group, implying that professional ethics are specific to the group. This principle leads to the idea that engineering ethics apply only to engineers. Thus, we can narrowly define engineering ethics as a set of rules of conduct by which only engineers abide. The moral acts that guide the professional life of engineers are called engineering ethics and may include a variety of factors such as design methods, safety guidelines, and testing procedures (Harris et al., 1996).

Leadership has been defined as the "process of social influence in which one person can enlist the aid and support of others in the accomplishment of a common task" (Chemers, 2002, in Riggio, Murphy, and Pirozzolo, p. 140). Broadly, leadership is a process that guides people for change and allows them to take actions according to their wills and desires. In fact, leadership is a blend of managerial efficiency and monarchial power (Michael, 2005). Looking at the context and application of leadership in engineering, it is the ability of the leader to guide the whole project and influence other people to meet the schedules and customer quality requirements while working within specified time and budget constraints (Hinkle, 2007).

Lastly, perception has been defined as "judgment derived from its proper object" (Potter, 1995, 309). Perception is image without any connection to word or classification or relation to other things. Another definition of perception is that it is "knowledge produced from sense-object contact" (Potter, 1995, 309). So, in the context of this topic, perception of ethics and leadership is the faculty member's ideology of these terms - the image that the individual has in mind with reference to the terms.

The study focuses on measuring engineering faculties' current perception of ethics and leadership training. First, the study provides definitions of different related terms in the framework of ethics and leadership. The authors conducted a detailed study of existing literature about the topic and identified variables in the literature review that follows. The study proceeds, based on the use of qualitative methods of collecting data, followed by an analysis of the data based on the literature and research experience. The authors then draw conclusions based on the arguments and a synthesis of the literature and collected data.

\section{LITERATURE REVIEW}

Engineering ethics is a concentrated term that has specified meanings. Although differences exist in practices at different institutions, the core idea is the same. Engineering ethics mainly focuses on acknowledging the overall mission of the professional that can contribute to human welfare. This key area, when blended with public safety, health, and welfare, and protection of the environment, takes the form of engineering ethics (Colby \& Sullivan, 2008). Engineering ethics, broadly, involves honesty to professional activities and loyalty to both employer and client, spurring the engineer to act in their best interest. Important criteria involved are fairness and maintenance of confidentiality, establishment of intellectual property rights, and prevention of unfair competition. Ethical code for engineering does not formally encounter the issue of globalization; however, an important variable involved in the determination and formation of ethical code for engineering is its intercultural impact (Downey, 2005).

In 1993, Hanson, McCarthy, and Paur studied the variables that can shape the ethical environment for engineering students. For example, they note that the efforts of students are more important in learning when compared to the efforts of faculty. Students learn $80 \%$ of the studies themselves and the remaining $20 \%$ is the ethical gap that they are required to fill. Hanson et al. claim that the most important component for development of an ethical environment for engineering students is the concern of the faculty, which is demonstrated by the time the 
faculty is assigned to students. In addition, the inability of faculty members to effectively communicate creates ethical dilemmas in class. The role of the advisor is also important in shaping the ethical environment, and can also be related to the faculty's concern for students. Lack of guidance by faculty members in counseling studies also creates ethical restlessness among the students. Faculty responsiveness is another leading factor for development of the ethical environment. Undue strictness regarding tenure and grading, as well as favoritism and influence peddling, are other factors that can keep students away from directly communicating with faculty and learning ethical principles. The introduction of high-technology devices also can lead some students to adopt unfair and unethical practices; for instance, hacking, high-tech calculators, and so on. Those students who work without groups and high-technology devices usually suffer in terms of class performance when compared to other students. And although the academic policies and faculty serve as guides to adopting fair methods and approaches, the fact that faculties allow group work by students shows that even the faculty perspective regarding ethics is not clear.

The ideas of Colby and Sullivan (2008) are endorsed by those of Vesilind (1996). However, Vesilind links engineering ethics mainly with academic integrity. Academic integrity is a way to professional engineering integrity. A student who maintains confidentiality and loyalty, avoids plagiarism, and adopts other ethical stands, as mentioned by Colby and Sullivan, can become an ethical engineer.

Up until now, it has been established that the there are few variables, such as faculty interest and faculty responsiveness, which can shape the ethical environment for engineering students. This perspective leads to another query: How can ethics training be given to students? Engineering ethics is currently being taught in undergraduate courses and in the media materials and methods of instruction used in engineering. These include videos, Internet material, media packages, papers, reference texts, and so on. Engineering ethics is taught to students by the adoption of a number of approaches, such as case studies, professional codes, humanist reading, theoretical grounding, ethical heuristics, and service learning (Haws, 2001). In 2001, Pfatteicher further elaborated on the concept by including faculty's perception in the issue of students' education in engineering ethics. The author compares teaching with preaching and justifies that a vital aim of teaching engineering ethics is to ensure, in an ethical manner, that students understand their professional responsibilities. Faculties need to have a clear perception that they need to inculcate the values in the student instead of the student just memorizing them. Colby and Sullivan mentioned that only a few institutions are offering formal courses for teaching engineering ethics, and even those that are undertaking this task still lack the rigor of the faculty in actual practice. Pfatteicher suggests that faculties should have an objective of clarifying the perception of engineering ethics and its value to students. Both students and faculty should have a clear understanding of the distinction between engineering ethics and an ethical engineer. Moreover, both students and faculties must be able to solve problems that students might confront in the engineering profession while they are acting ethically.

In 1999, Stephan surveyed 242 American institutions to identify their rigor for teaching engineering ethics. Out of 242 institutes, only $27 \%$ had treated the engineering ethics course as a compulsory one. About $75 \%$ of the institutes allowed their students to get a professional degree in engineering without a single course in engineering ethics. In contrast, $27 \%$ of the institutions that were offering the course did not provide in-depth instruction. Brigham Young University had the highest number of engineering graduates; i.e., 357. However; it had allocated 14 credits to religion, although there was no single course that dealt with general or engineering ethics. Marquette University and the University of Norte Dame had the second highest number of graduates, with 261 and 209 graduates, respectively. Both of these universities had allocated courses on philosophy and theology; however, there was no specific course for engineering ethics. Abhum University, with 390 graduates, had only one basic course "Introduction to Ethics"; Colorado School of Mines had only the course - "Nature and Human Values." In the same way, accredit schools, such as the U.S. Air Force and the U.S. Army academies, Stanford University, and Stony Brook University, had only one course for ethics. This sampling shows that there are relatively few institutions that devote extensive efforts to ethical instruction. A larger group undertakes a single course, and a majority does not require even one course dealing specifically with ethical content.

Loui (2005) established the need of ethics education in engineering. He analyzed from a survey that courses in engineering ethics reinforce the students' previous inclinations to act morally. By studying ethics courses in engineering, students express enhanced self-confidence in identifying moral problems. Such a course also helps them in finding the solutions to such problems. The students' surveys clearly identified that they benefited most 
from studying cases that covered a diverse perspective. They expressed that, with the help of these courses, they found that engineering work has a strong link with social consequences.

Loui performed his longitudinal study by comparing the same students before and after they were taught the ethical engineering course. The same students expressed that they really identified the need of ethics in engineering after they had studied the topic. He says that engineers have explicit responsibility for public safety and are responsible for caring for the environment and the general public as well. He conclusively suggests that ethical education in engineering, particularly in the civil and electronics areas, is a must, although it is equally important for computer and chemical engineering. Every institute must undertake these courses for a better society and more responsible professionals. In 2005, Loui arrived at methods for teaching engineering ethics, following identification of the need in 1999. For example, an appropriate method is video-based learning. Loui utilized the longitudinal study method and tested the participants with a video-based method, and then surveyed them. He found that a clear idea of thought about engineering ethics was developing in the participants. He also established that once a student is a fully accredited engineer, the chances are rare that he may accept the ethical considerations provided by books. However, students showed strong positive growth during their participation as students in the video-based method for adopting a ethical research method.

Naturally, if we synthesize Pfatteicher's results with those of Loui, we can link the institutional lack of teaching engineering ethics with the faculties' perceptions about ethics training. Important universities and institutes, such as the U.S. Air Force Academy, Stanford University, and others, are not considering the engineering ethics courses as more than a formality. The courses are designed by upper-level faculty members and they are the ones who decide what is important to teach. This data shows a clear relationship to the idea that a university will teach an ethics of engineering course, only if the faculty allows it or considers it important. Currently, there is no rigorous advancement toward offering such courses to engineering students, which highlights three important questions:

1. What is the current perception of faculty toward engineering ethics?

2. What are the preferred methods of teaching engineering ethics to students?

3. What benefits do faculty members see to a focus on engineering ethics?

\section{ENGINEERING LEADERSHIP}

As mentioned, leadership also is an important characteristic that is required for engineering professionals. Although the importance for leadership skills has been recognized, this area still has not traditionally been a part of the curriculum for engineering students. A leader must have at least three characteristics - effective communication, higher vision, and decisiveness. A leader also has four ethical dimensions - ethical character, ethical relationships with people, ethical endeavors, and ethical communication. A leader is one who tactfully deals with people, builds strong alliances, and persuades rather than coerces. His character should be enlightened by honesty, integrity, and the ability to handle unjust criticism, and he should be a master of paradox. He should endeavor to make instant decisions, set goals, be results-oriented and innovative, and make a constant effort. Last but not least, a leader must have a pattern of strong communication. He should be a master in public speaking and should be able to communicate and reaffirm his visions, constantly influencing others about those visions. These capabilities typically are not injected in the students of engineering, which may yield alarming results for future engineers because they may not be able to lead a project (Sabatini, 1999). A leader is not only required in politics, but also plays an integral part in institutions. The educational system needs instructional leaders who lead others in the process of change and who energize and encourage others to focus on teaching and learning. Such leaders will be capable of inculcating leadership skills in students (Rover, 2006).

Engineering is basically the use of science and technology to provide benefits to the society. In this regard, engineers have an in-built responsibility for their decisions and they are explicitly responsible for public welfare. Engineers should have a clear idea in their minds about what engineering leadership is. Similarly, the academics and faculty who teach engineering students should be highly concerned with this subject. They must help to ensure the maximum contribution from the world fraternity of engineers (Muroyama and Stever, 1988). 
In present times, there is need to teach the attributes of personal core values and character in leadership training. For this, an initiative is required by faculties to create a vision and course of action for teaching leadership skills. Attributes of leadership include traits, such as the ability to decide in times of uncertainty, responsibility, resourcefulness, and flexibility. Other important characteristics of the engineering leader include a focus on equity and diversity, vision, self-awareness, commitment to self-improvement, inquiring and dialoging, advocacy, and the development of interpersonal skills. The aforementioned traits are particular to all types of leaders; however, the engineering leader must be aware of the needs of the customer or beneficiary and must also have enterprise awareness and the ability to think creatively and imagine the possibilities. An engineering leader must have technical knowledge and be able to think critically, along with being able to implement solutions (Capabilities of Effective Engineering Leaders, 2009). Certain methods could be used to teach leadership skills. In 2005, Chenoweth discussed the methods through which leadership can be taught to undergraduate students. The author points out that presently only one course in computer science was currently offered to students.

Prior to this offering, the department at Rose-Hulman was in the practice of awarding an engineering degree with a single course in leadership training, although most of the alumni were working in leadership positions, such as project managers, directors, chief software engineers, and the like. Many students performed leadership activities in their day-to-day job activities, as in the lead development of a software design engineer. To acquire the needed leadership skills, most of the alumni have taken one or two additional business management courses or acquired an MBA, and although it's a worthy undertaking, an MBA is not an alternative to acquiring engineering leadership skills. Chenoweth identifies a major gap in education. For example, in the aforementioned department, a strong focus was put on developing the management skills of architectural and petroleum engineers, while leadership skills training was allocated only to those in construction.

The need for leadership training in engineering education has now been identified at different levels. Along with MBA programs, different universities are also offering standalone certification. For instance, Northern University provides standalone certification in engineering leadership, which focuses intensely on developing a deep understanding of the scientific framework of knowledge that supports engineering practice and the assessments of the proposed technological solution (Engineering Leadership, 2009). In spite of these advances, few institutions are taking such a keen interest in leadership development for engineering students; and even at Northern University, there still is no particular arrangement for including this course in the formal engineering degree program. Up until now, it has been well established that many institutes understand the importance of leadership courses; however, they are reluctant to include the courses into their curriculum in a practical way. As noted, some universities that have identified the need are training their students through standalone certifications; but why are they not including the training within their core curriculum? Felder and Silverman (1998) have identified that teaching leadership is a difficult task and requires that a number of methods be considered before it is taught. On the basis of this fact, it can safely be assumed that this is a difficult task to accomplish and one to which universities are responding by designing standalone courses for graduates. Some teaching styles Felder and Silverman describe in this context include motivational learning and emphasizing practical problem solving and the scientific method with regular use of interactive mediums. Incorporating students' thinking skills when teaching leadership is the essential part, and this can be accomplished through an emphasis on expressing opinions, other appropriate assignments, and increased discussions.

Leadership education is an important need for students enrolled in engineering; however, this need has not yet been truly identified. In other words, it seems that it has been identified, at least by a number of sources, but that it hasn't yet been given the significance and priority necessary in the engineering educational curriculum. Both leadership and ethics are taken as side perspectives of the disciplines, which is harming the student in practical life when he or she has a strong need to act ethically and as a leader in engineering.

As many authors have identified, leadership skills can be taught in a number of ways, including reflexively and through inculcating practical examples. However, the first priority is to understand the faculty's perspective. Leadership training will be fully immersed within the engineering education program only after the faculty's perspective about leadership and ethics training has been identified and incorporated into the solution for closing this gap. Unanswered questions include, "Why, in spite of understanding the whole phenomenon, are faculties not properly catering to this subject as an inevitable part of teaching? Or do they not yet understand the importance of 
leadership and ethics training? Have they understood and taught the courses conceptually and thought that was all they could do for teaching the course?" The literature provides a comprehensive overview of the technical issues but does not provide a clear insight on this issue. For that reason, this study focuses on finding the actual perspective of various faculties on the role of ethics and leadership education for engineering students.

\section{METHODOLOGY}

As identified in the literature, there is a need for insight into faculty's perspective on ethics and leadership training in engineering education. For the purpose of collecting opinions, the authors selected the survey method in which the authors used the interview as the tool for data collection. Deciding on the interview type was a difficult task because this issue has no black and white results. The fact that the authors could derive more from a discussionbased interview determined which interview method the authors selected for data collection. Interviews are a better methodology for this type of study because they can help to explore people's thoughts and feelings about a particular topic (Focus Groups and Interviews, 2009). Interviews were ideal because they helped to attain an indepth insight of the participants on this focused topic (Rabiee, 2004). The authors selected participants on the basis of their knowledge of and experience with the particular subject. All participants belonged to the engineering faculty of different engineering departments in the University of Kuwait. Because ethics and leadership skills are related to the core of engineering, the authors collected the insights of faculty members of almost all subjects. In this exercise, faculties from all areas, including religious studies, communication studies, and engineering subjects such as artificial intelligence, petroleum formation, basic architecture, and so on, participated in the interviews. The authors selected eight faculty members for the interview. The authors allocated a time slot of 90 minutes for each participant, which was extended to 120 minutes in three cases as a result of an extended discussion.

In selecting participants for interviews, the authors used the diversification approach. The authors approached different faculties so that there could be more flow of extended knowledge. Moreover, while selecting participants, the authors took care to include females, as well as fresh graduates, to attain a diversified base of knowledge from different people. The authors selected participants purposively and by looking carefully into the prospectus of colleges. After the authors found the required participants, the authors acquired written permission from each participant and asked their convenience for the allocated time slots. Initially, five faculty members refused to provide any information; however, later, through modification in the permission letter, the authors attained permission from the rest of the participants.

The authors conducted all interviews in college seminar rooms and conference rooms. During the interview, the authors ensured there would be no interruptions from external aspects, such as mobile phones or students. For this purpose, the authors acquired special permission in the letter to conduct the interviews after regular college hours, which all faculty members consented to.

Interviews began with the following statements:

1. As we know, we are here for a specific purpose - to collect your valuable opinion.

2. There are no right and wrong answers in this discussion.

3. The authors ask you to feel free to give opinions and discuss your ideas. Please express what you think and why you think so.

After this introduction, the interview was formally started. It was a semi-structured interview because the only topics for discussion were prepared in advance. The interview questions were limited because the intention was to stay with the topic and hear more from the participants, including aspects they disagreed with. The interview covered the following topics:

1. Importance of leadership training in engineering

2. Importance of ethics training in engineering

3. Satisfaction level of faculty members with the ethical and leadership training of engineering students in the current curriculum

4. Importance for recent graduates to have learned about the ethical leadership role 
5. Whether a diploma in ethics and leadership in later stages of an engineer's career is more useful

6. Ethical gaps in students and ways to correct them

7. Discussion about the following perspectives:

a. Student ethics training is only the responsibility of religious faculty and parents.

b. Leadership is a born quality and we cannot inculcate it into every student; however, we can polish, and so we do, through one course.

8. Performance of alumni in connection with ethical and leadership engineering studies and their current job positions

9. Proposed changes in curriculum for ethics and leadership training in engineering courses

10. Discussion about the following view: "Studying and teaching engineering is a full-time job and all ethical and leadership attributes should be inculcated into students before they enter into professional engineering. We can surely mould them to engineering ethics and leadership principles with just one course."

The authors made adequate recording arrangements with the permission of interviewee and they recorded all conversations. The authors conducted pilot testing on two participants. During the interviews, the authors noted reflective passages in the notes. For every interviewee, the authors allotted a separate sheet on which the authors noted particular ideas. The authors first sketched the ideas, in the form of margin notes, while participants were speaking. After the interview was done, the authors wrote a summary of the margin notes on the field notes to make the idea more comprehensible. The authors then developed metaphors based on different ideas expressed during the interviews. The authors then developed the codes and wrote code memos for qualitative interview passages. The authors developed and analyzed the frequency of codes using the QDA software. The logical links the authors developed for a theory, based on the frequency of codes, are presented in a later section.

\section{DISCUSSION}

From the data the authors collected in interviews and based on the analysis the authors performed, they have traced the faculty members' perceptions about engineering ethics and leadership. They could sense a definite difference between the knowledge levels of different faculty members about the engineering ethics and leadership requirement. As highlighted in many questions, generally a metaphor developed among the respondents that engineering is a full-time job and they found there to be no place that could specifically be allocated to ethics and leadership training. As with religious education, they found that allotting a single course was sufficient because the student had already come through all the courses of ethics being taught in his initial classes. If a relationship is made between this point of view and the other point of views given by very few participants, a true picture forms of the faculty members' perceptions of engineering ethics and leadership. Some ideas were provided that support the assumption that students are fresh graduates when they leave the college and they cannot find a leadership position in the beginning. They need vast experience to approach positions, such as team leader, project manager, or chief developer.

Universities always want to stay in touch with their alumni because they are the source for likely career progressions for their upcoming students. Moreover, they are the source of data for many universities. These two factors particularly motivate faculty members to defer the ethics training. They do not cancel it; rather, they only postpone it to the period in the alumni's career when they get some demanding job. This perspective appears to be more rational; however, its foundation is weak. Looking at the perspective underlying the literature of Amjad (2008), Colby and Sullivan (2008) and Harris et al. (1996), it is not valid to defer any part of the engineering student's study. The points of view of Amjad and Harris et al. focused on the role model of faculty as well as on the ethical and leadership requirements in engineers' day-to-day activities. Moreover, it can surely be interpreted from the literature that students will never be able to perform well unless they have leadership abilities and a strong ethical foundation. So what about this contradiction of opinions in terms of faculty members' views about those trained as engineers first getting the demanding job and then pursuing leadership and ethics training? There appears to be a deadlock between the two views since an engineer's career cannot progress unless he is ethical and sincere in his job and can lead his crew well. In contrast, his faculty would not train him in these skill areas unless he gets a job that demands from him leadership and evidence of ethical behavior and values. 
In addition to this, a theory floated during the discussions about faculty members' satisfaction level of current ethical practices and the gaps they felt in their student's ethical behaviors. Surprisingly, almost $80 \%$ of the members interviewed were unsatisfied with the level of their students' ethical behaviors. For instance, one participant stated, "Students act in strange ways sometimes; asking them not to waste the resources most likely results in very rude answers." Another participant stated, "I expected that they could form their study group themselves; however, I was disappointed to see that they spent a whole week in so forming, and the groups were not even appropriate." Yet counter to this opinion, participants maintained that students should have learned ethics correctly from their previous faculty, their environment, and, of course, from their parents. They did not associate engineering ethics and leadership skills with these minor issues. Loui (2005) and Pfatteicher's (2001) ideas also work in the same aspect, however in a different perspective. Engineering ethics is not merely leading in a nice way; rather, it is about a sense of responsibility. Of critical importance, this also includes caring for the scarce resources of government, the public, and the employer. Similarly, forming study groups can be seen as an initial step toward team formation. If a group of 50 engineers enrolled in the study program cannot appropriately form a study group, it is unlikely that they can manage a number of masons, coders, or extractors in their relevant fields.

Apart from these viewpoints, several interview participants also stated that there is a need to change the engineering curriculum slightly for both ethics and leadership. For this purpose, a maximum of two courses could be offered since this would serve the purpose. The participants found no particular gaps in alumni performance; nevertheless, to brighten the prospect of engineering and to make the study more perfect, the engineering curriculum should be changed. Loui (2005) and Felder and Silverman (1998) support this idea and state a wide variety of ethical and leadership training can be offered through different methods. Teaching ethical courses will have a moral impact on engineering students and, with constant emphasis, there would be less chance they will indulge in unethical engineering activities.

\section{VIEWPOINT}

Significant challenges are identified in the study which we need to focus. First of all, the study concludes with the fact that faculty are lacking in the area of clear perception on leadership. The challenge of the time is to prepare students for the organization having critical need of leadership. As identified by Bolman and Deal (2008), organizations in the U.S are suffering from cluelessness which is due to incompetent management and unhealthy leadership traits in organization. The authors use illustrations from politics as examples of incompetent leadership and provide examples from the political event of the U.S in lieu that structural leadership and management in organizations is weak. To support the same idea, they have exemplified the Enron and Anderson failures as indicators of weak and clueless management. The current challenges posed by the study are in line with the problems identified by Bolman and Deal. They suggest that there is a need to reframe the organizations based on the fact there is lack of coherence in the organizations. If the authors' link up this view with the one extracted from the study, it can surely be formalized that organizations are facing a management crisis as their managers lack insight.

The scenario can be explained more clearly with a hypothetical situation. When a student completes an engineering degree from the university, he should be ready to lead the team and should be able to work in capacity of a project manager. Moreover, he should be able to assume the responsibility of an ethical engineer. Being a fresh graduate, he has more responsibility to prove his skills in every area in which he has graduated. Looking at IT project failures all over the world, the ratio is quite high. One of the main reasons is that projects do not complete in time and companies have to pay more for their non-leader engineers. Such engineers are usually not capable to handle the whole project in the beginning of their career and could not lead the teams. Knowing this, companies hesitate in appointing fresh engineers as project managers. The general trend in almost all countries is to employ fresh engineers at the clerical level in which the main task is to assist senior managers. Looking from the perspective of Bolman and Deal, what is experience? Why do experienced people have more ability to make the organizations work better? Linking up this context with the study context, experience can be termed as ability of an individual to lead and manage. Technically seen and accepted, fresh graduates have more technical skills than experienced people working in organizations for longer period. They are more equipped with technical know-how, software and simulation programs, but weakness of their ethical and leadership enforce them to start work at a clerk level. 
Developing the human resource frame from Bolman and Deal's task, it is important to note that the central goal of such a frame is to have a fit between organization and individual. Observing from personal experience, any engineer will be able to work in an organization when he will fit in the overall company environment. Organizational environments today are very much competitive. The critical task of human resource is to develop a technical structure where engineers align with the technology and environment of the organization. Comparing it with the challenges posed in the current study, teachers are intentionally hindering to provide the students with alignment skills with the studies. They are only preparing the students to perform a pre-designated task instead of creating an ability to draw their own task. Moreover, teachers are not training their students on ethical grounds which also hinder them to focus on team-building, having shared goals, and to communicate openly. For instance, it is a common observation that fresh graduates need more training when they are hired by an organization for both technical skills and organizational culture learning. This is due to the fact that they lack ethical skills which they should have studied during their education. As identified in the study, one or two courses cannot meet the requirement of ethical learning. There is a need to take practical learning steps towards teaching of ethics and leadership.

Based on the challenges and review of Bolman and Deal, perception of teachers about ethical and leadership training is required to alter. Most important, when their vision will improve, this will put an impact on their teaching methodology and ability to input the ethical stance in students. There is need to change the structure and frame of teaching to improve the current lags in teaching. Structure and frame by regulatory authorities is required to upgrade. Such governing bodies are required to put more emphasis on practical implementation of ethics and leadership. For this purpose, the pre-built model of Cindey Marshall's scenario can be utilized. By using this structural frame work, governing bodies, teachers and students are required to look into high risk areas which are potentially threatening to new recruitments and fresh graduates. However, Human Resource needs to train the fresh graduate teachers. The teachers must understand that employers of fresh graduates need a response of their training. They want fresh graduates to serve in the best interest of both employer and company. Proper ethical and leadership training can enable fresh graduates to understand the level of expectation associated with every job. Teachers should give students the freedom of expression as well enable them to get inspiration from existing ethics and leadership models, examples, and from day-to-day scenarios.

Along with this, Bolman and Deal's idea of training and negotiating is required. Universities are somehow logical in this context that they need their alumnus, but it not ethical on their part to shrink the learning for their personal interest. Governing bodies are required to conduct negotiations with the alumnus. Moreover, governing bodies should consider the future recruitment opportunities of the upcoming graduates. Alumnus committees are working all over the world and interested universities can even make them better. A proper building of a human resource frame, with structural focus on goals of all parties, can reduce current lags in ethical and leadership training. This is particularly important for the teachers who deliberately are withholding knowledge for their future fees or jobs benefits.

\section{CONCLUSIONS}

Engineering is one of the core disciplines students are pursuing today. This study focuses on the faculty's perceptions about the role in the ethics and leadership training aspect of students' education in an engineering university. Faculties have always been a role model for their students, and their role is more diversified than merely putting information in the minds of students. In many respects, they are virtually as responsible as parents are for students' behavior and values, including their ethics. It is absolutely critical for engineers to perform in ethical ways. Engineers are responsible for the resources assigned by stakeholders and for the health and safety of the public; therefore, they assume a huge ethical responsibility. That responsibility, however, encompasses not only ethical values; engineers are also required to act in a leadership role. They are responsible for leading the crew, meeting the budget, and completing requirements within a designated timeframe. A number of studies, such as those that Loui, and Felder and Silverman discuss, have identified the importance of ethics and leadership training in engineering courses. Pfatteicher and Hinkle have presented similar studies endorsing the importance of ethics and leadership in engineering. The literature concludes that universities are now beginning to recognize the importance of engineering ethics and leadership; however, the curriculum in these areas has not been widely implemented. Most universities are undertaking single courses to engineering students or offering stand-alone certification in engineering ethics and 
leadership to professional engineers. The literature review evokes questions about faculty's perception of both ethics and leadership. Only by identifying these perceptions can we come to a basic understanding about 1) the relationship between them and the current ethics and leadership training in engineering education and 2) how to modify the curriculum to more fully prepare students for their professional life as engineers.

To find the faculty's perception, the authors applied an interactive study design. They asked the faculty members to explain their perceptions of the ethics and leadership issues presented. For best interaction and most complete collection of data, the authors used the survey method. For data collection, they conducted interviews because they allow more flow of ideas on a specific topic. The authors interviewed eight people who all granted specific permission for the interviews. Following the data collection, the authors performed the data analysis with the help of the QDA software, the field notes, and relevant coding. The authors observed different viewpoints during the interviews, which can be summarized to say that the faculty who had been interviewed do not perceive the study of ethics and leadership as an important study for recent engineering student graduates. Instead, they assume it is an important part in later stages in an engineer's career and they intentionally delay the leadership and ethics training until then. At the same time, they are aware of the fact that there is an ethical gap. They attribute that ethical gap more to the students' previous educational institutes and to their parents. According to the engineering faculty the authors interviewed, it is of utmost importance to teach the technical aspects of engineering; and while ethics and leadership skills can even be taught in later career stages, at the present time, little modification can be made to upgrade the curriculum to better incorporate engineering ethics and leadership education and training.

In light of the above study the authors conducted, one can draw the following conclusions from the various faculties' perceptions about engineering ethics and leadership training:

Engineering students should be more concerned with the technical aspects of engineering; they can attain the leadership and ethics training later in their careers. Faculties intentionally delay ethics and leadership training because the universities want to stay in contact with their alumni. Moreover, offering stand-alone certification in these areas may be a better idea in later stages of an engineer's career. These expensive certification courses help the universities to generate more funds and to prosper, and although current students have some ethical gaps, those are, in part, related to the focus on technology development. The gaps are also evidence that students' previous faculties and educational institutes could have better served them in these areas. The current engineering curriculum is fine as is because most of the alumni are working in executive positions without any problems from lack of leadership and ethics training. To inculcate an added level of ethics and leadership training in order to remain current with international standards, a few courses can be added, but they must not dominate the core engineering courses.

The study has looked widely into the aspects of this issue; however; there still are limitations to the study. The study considered only the faculty's perception; the authors could not cover the students' requirements and views due to the time constraints. Moreover, there is no way to confirm whether the alumni have been able to progress in their careers with smoothness and ease as their former faculty members claimed. Engineering ethics is widely required in all types of leadership training; however, leadership training and abilities may not be required in a similar manner by all engineering disciplines. There also is a need to look into the degree of engineering ethics and leadership associated with different fields of engineering such as computer science, petroleum, civil, and so on.

\section{AUTHOR INFORMATION}

Dr. Abdullah AlSagheer is an Assistant Professor of Management at the e-School of Quality and Business Management at the Hamdan Bin Mohammed e-University. He is teaching undergraduate courses level such as TQM Implementation, Capstone Project. In addition, he is teaching graduate courses level such as Strategic Management of Innovation and Technological change. Dr. AlSagheer has PhD in Education and Human Resource Studies specialized in Interdisciplinary Studies (Industrial and Human Recourse Management Engineering) and M.Ed Education and Human Resource Studies specialized in Interdisciplinary Studies (Industrial and Human Recourse Management Engineering) from Colorado State University (CSU). He received Master of Science in Electrical Engineering specialized in Integrated Systems \& Strategic Project Management. His undergraduate degrees were Bachelor of Science in Computer Engineering and a double major in Bachelor of Science in Electrical Engineering 
from California State University Long Beach (CSULB). Dr. AlSagheer research focuses in Strategic Management, Capstone Courses, Entrepreneurship and Leadership, Total Quality Management, Ergonomics and Human Factor Engineering, Curriculum Development, Human Resource Management, Management Training, Teamwork, Innovation Strategies. Engineering Management \& Industrial Engineering.

Areej Al-Sagheer worked as Senior Accountant in Kuwait Petroleum International Limited (KPI-Q8). Al-Sagheer received her Bachelor of Science in Accounting \& Auditing from Kuwait University. Al-Sagheer got her MBA at Colorado State University. She has experience in the industrial field as Assistant Accountant Treasurers in the Kuwait Oil Tankers Company (KOTC) and Financial Assistant / General Accountant and then Senior Accountant in the Kuwait Petroleum International Limited (KPI-Q8) from January, 1997 until today. Her research focuses Audit Accountancy, Business Leadership, Business Education, Corporate Finance, Risk Management and Human Resource Studies.

\section{REFERENCES}

1. Amjad, M. (2008). Role of the Teacher. Retrieved online from http://www.renaissance.com.pk/deisma95.html

2. $\quad$ Bolman, L., \& Deal, G. (2008). Reframing Organizations: Artistry, Choice and Leadership, $4^{\text {th }}$ ed. Willey higher education.

3. Capabilities of effective engineering leaders (2009). Retrieved from Gordon-MIT Engineering Leadership Program, Information for Students, Retrieved online from

4. $\quad$ http://web.mit.edu/gordonelp/Capabilities.html

5. Chemers, M. M. (2002). Cognitive, social, and emotional intelligence of transformational leadership: Efficacy and effectiveness. In R. E. Riggio, S. E. Murphy, and F. J. Pirozzolo (Eds.), Multiple Intelligences and Leadership (pp. 139-160).

6. Colby, A. \& Sullivan, W. (2008). Ethics teaching in undergraduate engineering education. Teaching Journal of Engineering Education (pp. 327-338).

7. Downey, G. L. (2005). Are engineers losing control of technology? From 'problem solving' to 'problem definition and solution' in engineering education. Keynote address at World Congress of Chemical Engineering. In Chemical Engineering Research and Design 83(A8), 1-12.

8. Engineering leadership (2009). Graduate School of Engineering. Retrieved online from http://www.coe.neu.edu/gse/sc el.html

9. $\quad$ Felder, R., \& Silverman, L. (1988). Learning and teaching styles in engineering education. Engineering Education, 78(7), 674-681.

10. Focus groups and interviews (2009). Retrieved online from http://www.chronicpoverty.org/page/toolboxfocus-interviews

11. Hanson, T., McCarthy, W., \& Paur, K. (1993). Student/professor ethics in engineering academia. Journal of Engineering Education, 82(4).

12. Haws, D. (2001). Ethics instruction in engineering education: A (mini) meta-analysis. Journal of Engineering Education (pp. 223-229).

13. Hinkle, G. C. (2007). All engineers need leadership skills. Today's Engineer, IEEE USA On Line, Retrieved online from http://www.ieee.org/organizations/pubs/newsletters/npss/0607/leadership skills.html

14. Loui, C. M. (2005). Ethics and the development of professional identities of engineering students. Journal of Engineering Education (pp. 383-390).

15. Michael, J. C. (2005). Leadership. Harvard NOM Working Paper No. 06-05. Retrieved online from http://ssrn.com/abstract=744786

16. Muroyama, J., \& Stever, G. (Eds.). (1988). Globalization of Technology; International Perspective. The Council of Academies of Engineering and Technological Sciences.

17. Norman, D. O. (1984). Practical Reason, Aristotle, and Weakness of Will. Minneapolis: University of Minnesota Press.

18. Pfatteicher, S. (2001). Teaching vs. preaching: EC2000 and the engineering ethics dilemma. Journal of Engineering Education (pp. 137-142).

19. Potter, K. H. (1995). The Encyclopedia of Indian Philosophies (p. 309). 
20. Rabiee, F. (2004). Focus-group interview and data analysis. Proceedings of the Nutrition Society, 63, 655666.

21. Rover, D. (2006). The academic bookshelf: Curriculum leadership. Journal of Engineering Education (pp. 185-188).

22. Sabatini, D. (1999). Results of a student discussion group on leadership concepts. Journal of Engineering Education (p. 255).

23. Stephan, K. (1999). A survey of ethics-related instruction in U.S. engineering programs. Journal of Engineering Education (p. 459).

24. Vesilind, A. (1996). Using academic integrity to teach engineering ethics. Journal of Engineering Education (p. 41). 